\title{
Todorov Nicola, La Grande Armée à la conquête de l'Angleterre, le plan secret de Napoléon
}

Paris, Vendémiaire, 2016, 295 p.

Philippe Boulanger

\section{(2) OpenEdition}

Journals

Édition électronique

URL : https://journals.openedition.org/geohist/1372

DOI : 10.4000/geohist. 1372

ISSN : 2264-2617

Éditeur

Association française de la Revue de géographie historique

Référence électronique

Philippe Boulanger, «Todorov Nicola, La Grande Armée à la conquête de l'Angleterre, le plan secret de Napoléon », Revue de géographie historique [En ligne], Comptes-rendus, mis en ligne le 20 novembre 2017, consulté le 12 juin 2021. URL : http://journals.openedition.org/geohist/1372 ; DOI : https:// doi.org/10.4000/geohist.1372

Ce document a été généré automatiquement le 12 juin 2021.

Ce(tte) œuvre est mise à disposition selon les termes de la Licence Creative Commons Attribution Pas d'Utilisation Commerciale - Pas de Modification 4.0 International. 


\section{Todorov Nicola, La Grande Armée à la conquête de l'Angleterre, le plan secret de Napoléon}

Paris, Vendémiaire, 2016, 295 p.

\section{Philippe Boulanger}

\section{RÉFÉRENCE}

Todorov Nicola, La Grande Armée à la conquête de l'Angleterre, le plan secret de Napoléon, Paris, Vendémiaire, 2016, 295 p.

1 Nicola Todorov, l'un des spécialistes français de la période napoléonienne, s'intéresse dans ce nouvel ouvrage à un grand projet stratégique bien mal connu du grand public : la préparation de l'invasion de l'Angleterre après la défaite française de Trafalgar en octobre 1805. Dans un style toujours précis et une argumentation fouillée grâce à la consultation des archives et de la correspondance de Napoléon, l'ouvrage s'articule en 11 chapitres abordant tous les aspects d'un tel plan stratégique. Nous apprenons donc beaucoup à la fois sur l'histoire et la géographie d'un empire qui s'apprête à reconstruire sa flotte de guerre en puisant dans toutes ses ressources à partir de 1810 . Car Napoléon, contrairement à une idée reçue, n'a jamais cessé de "venger vingt siècles d'insultes» et de mettre au pas son adversaire héréditaire. Des aspects politiques (l'échec du blocus continental) et économiques (l'aménagement des ports ou la concentration des moyens comme le bois de construction des navires) à ceux plus stratégiques et militaires (l'armement des navires, la formation des équipages de la flotte, la stratégie de l'Empereur entre autres faits), cette nouvelle étude nous ouvre les yeux sur un sujet méconnu, largement cantonné traditionnellement à la concentration des forces françaises (120 000 hommes) à Boulogne sur mer en 1804.

La thèse de Nicola Todorov est bien plus profonde. Elle vient renouveler une conception de la pensée stratégique et de la politique de Napoléon Bonaparte quant à la conquête 
de l'Angleterre. L'historiographie académique ne retient qu'une vision chronologique de celles-ci après-Trafalgar en sous-estimant la stratégie de l'Empereur sur la reprise de la guerre sur mer. Elle retient surtout l'idée que le blocus est la clef de voûte de la politique française. Or celle-ci doit être reconsidérée. Pour cela, l'auteur nous expose la vision et la politique de construction d'une véritable flotte dans un contexte difficile (échecs d'Aboukir d'août 1798 et de Trafalgar, pertes essuyées en ravitaillant les colonies, domination des mers par la Royal Navy). Un plan "secret ", décidé en 1810, doit permettre d'obtenir une force de 109 navires pour 1812. Cette marine d'après Trafalgar parviendra justement à son apogée en 1812 qui est une période de paix sur le continent. Napoléon envisage alors deux piliers dans sa stratégie maritime: la reconstruction d'unités lourdement armées permettant de reprendre possession de la mer avant de débarquer sur les côtes anglaises, le concept « d'opération générale ». Ce dernier consiste à "appliquer la stratégie de guerre continentale à la lutte maritime, en immobilisant les forces anglaises sous la menace exercée simultanément par de nombreuses expéditions d'escadres, de flottes de transports et de flottilles, afin de permettre à l'une des escadres substantielles de l'Empire de prendre l'initiative lorsqu'elle se trouverait en situation de supériorité locale face à la marine britannique » (p. 223). La stratégie maritime de napoléon consistait ainsi à concentrer les forces de l'océan dans la Manche, notamment à Brest malgré les contraintes de l'environnement pour sortir la flotte de la rade. Toute la thèse de l'ouvrage consiste ainsi à nous en expliquer la mise en œuvre jusqu'à l'été 1813. 